\title{
Discussion on the Borrowing of Behavioral Science Theory for Ideological and Political Education Methods
}

\author{
Lei Wang \\ School of Foreign Languages \\ Wuhan University of Technology \\ Wuhan, P. R. China
}

\begin{abstract}
On account of the great challenge faced by ideological and political education of college students, it's indispensable to borrow theoretical achievements from related disciplines. Behavior Science Theory is a subject that specializes in human's behavior principles. This paper expounds the referential significance of behavioral science on ideological and political education by using interdisciplinary research methods from three aspects, respectively need, incentive and motivation, holding the idea that behavior science could enrich the theoretical basis of ideological and political education, broaden research field, providing several referential practical methods for ideological and political education work, and enhancing effectively the pertinent and scientific nature of ideological and political education in colleges.
\end{abstract}

Keywords-behavior science; ideological and political education; need; incentive; motivation

\section{INTRODUCTION}

With the development of society, ideological and political education has encountered numerous new conflicts and discrepancies, multiply augmenting the difficulty of conducting ideological and political education. Facing this new circumstance, ideological and political education is imperative to extensively borrow every valuable scientific theory and method, self-renewing and ameliorating constantly to keep abreast of the steps of economic development and human's ideological transformation, with a view to keeping the exuberant vitality of ideological and political education. With this regard, behavior science possesses great referential significance, which assimilates research achievements from several disciplines, such as psychology, sociology, social psychology, anthropology, etc., broadens research fields of ideological and political education and provides several practical methods of resolving human's ideological problems. Some theoretical achievements, especially incentive theory, conduct research on human's need, incentive and behavior and also their mutual relations in line with the principle of psychological behavior development, and exert great practical value on the aspects of motivation stimulating, behavior inducing and initiative mobilizing.

\section{CATERING To Human's REASONABLE NEEDS IN IDEOLOGICAL AND POLITICAL EDUCATION}

Need refers to human's eagerness and desire for a certain target. Behavior science maintains that human's behaviors are subject to the dominance of certain motivation which is induced by diverse needs of human. Need gives rise to motivation and motivation decides behavior, i.e. need $\rightarrow$ motivation $\rightarrow$ behavior. It's evident that need is the motive power for producing behavior and the source of individual initiative. Admitting, envisaging, satisfying and guiding human's needs are questions of reality that our ideological and political education should firstly face up to.

From a long time, many foreign scholars have proposed their own need theories from diverse perspectives, such as Maslow's Hierarchy of Need Theory, McClelland's Theory of Achievement Need, Herzberg's Two-factor Theory, etc., of which the first one is the most representative. Maslow demonstrates that human needs occur in the form of hierarchy. According to their degrees of importance and sequences of occurrence, it is endowed with a pyramid shape of five levels from the low-level needs extending to the highlevel needs: namely, psychological needs, safety needs, social needs, esteem needs and self-actualization needs. He claims that only after gaining the satisfaction from the lowerlevel needs can the next higher-level needs be developed. Although Maslow's theory has some limitations, ignoring human's subjective initiative and the need to change sequence of hierarchy of needs on certain condition and a person's structure of need, he summarizes the basic contents of human's needs, divides the needs into two aspectsmaterial and spiritual, and points out the general rule of individual need development, which accords with the objective reality.

In effect, Marx and Engels had delved into the issues concerning the human's needs. Marx said: "Anything that human beings are striving for has bearing on their own interests". Started from human's needs, Marx and Engels studied any social relations and phenomena and their development law that occurred due to human's needs, insisting that the fundamental objective of socialism is to 
meet people's needs and make everyone "integrated development".

Marx and Engels's discourse on human needs has laid the methodological foundation of ideological and political education, and the need theory of behavioral science can provide methodological guidance for ideological and political education. Ideological and political education is not only a means but also an intentional activity. On the one hand, it can mobilize people's enthusiasm to accomplish tasks by changing people's minds. On the other hand, it studies human needs and may meet human needs through self-improvement, which is in accordance with human nature. Ideological and political education will merely be a castle in the air if it were divorced from the theory of human needs. And the following are some issues that we should pay special attention to.

- Have a proper understanding of personal needs. Ideological and political education is supposed to deal with the needs of every single individual. Motivations originate from needs. Only by having a grasp of the needs of educational objects can we get to know the motivations of them. We should understand and support reasonable personal needs, strengthen personal needs which have a positive significance, and persuade those who have unreasonable needs to give up.

- Guide the healthy development of human needs. According to Maslow's hierarchy of needs, human needs develop from low level to high level. Physiological needs and safety needs in the low level are easier to be met, and have limited influence on people's behavior motivations. While the realization of needs in the higher level, such as social belonging, esteem and self-actualization, demands everlasting psychological motivations. As a result, if we want to mobilize people's enthusiasm, we need to guide personal needs and sublimate them from low level to high level. As well, we ought to strengthen reasonable needs, and weaken those unreasonable needs that are divorced from social needs.

\section{DEALING WELL WITH MOTIVATION AND BEHAVIOR IN IDEOLOGICAL AND POLITICAL EDUCATION}

Motivation refers to the idea or thought that gives the reason for people's actions in order to meet a particular need. It is not only the internal motive that pushes our action, but also the immanent cause that stimulates people to take actions in order to achieve certain aims. Need leads to motivation, and motivation leads to behaviors. Motivation has a direct impact on people's enthusiasm and behavior effect. The practical implications of motivational theory for ideological and political education lie in how to stimulate educational objects' benign motivations, and how to fully arouse people's enthusiasm.

As a consequence, in practice, the characteristics of motivation have an important referential significance to the working mode and work characteristics of ideological and political education.

- In order to deal well with the complex relationship between motivation and behavior, we must make a concrete analysis of concrete problems in ideological and political education

Motivation leads to behavior, but between them exists a complex relationship instead of a simple linear relationship. And the relationship is shown in the following aspects: [1] the same motivation can lead to various behaviors. For example, if a student wants an iPhone, this motivation can lead to the following behaviors: behavior (1) saves money to buy the iPhone by working to earn money; behavior (2) saves up money to buy the iPhone by economizing; and behavior (3) gets the iPhone illegally. [2] The same behavior may originate from various motivations. For example, hard work may be caused by different motivations: motivation (1) enriches oneself for future development; motivation (2) aims to improve performance so as to win the respects of classmates; motivation (3) aims at getting scholarships to reduce the burden of family; and so on. [3] Reasonable motivations may lead to unreasonable or even wrong behaviors. For example, in spite of the parents' high expectations for their children, the children will perform poorer and poorer if the educational methods are not proper. Although the motivations of parents are good, their behaviors are wrong. [4] Wrong motivations will sometimes be covered up by behaviors that appear to be positive. For example, some people perform actively at work in order to get a higher position, while his motivation is to get personal interests after holding a senior position.

It can be drawn from the analysis above that the external behavior and the intrinsic motivation of a person can be either consistent or inconsistent. Therefore, we cannot judge motivation simply from behavior, nor can we judge behavior absolutely from motivation. Analyzing specific cases through its unique ways is rather crucial in ideological and political education.

- The characteristic of motivational implicitness require that ideological and political education should be advanced and predictable.

Motivation is a kind of subjective state, a psychological process. Thus it is implicit, which means the actual motivation of a person is often hidden deeply in his or her mind. The ideological and political education should focus the guidance of motivation on its target group so as to inspire people in their practices. To achieve this goal, the actual ideology and motivation of the educated targets must be well learned before we come to the final conclusion. Generally, good motivation leads to positive action, and the vice versa. From this perspective, we may find the key to ideology once the 
actual motivation of ideological and political education is grasped, thus we may get control in the whole process. From good motivation, we can foresee the behavior and results. Moreover, we can promote its realization through the application of ideological and political education. On the other hand, we can foresee the danger and damage to one's work through bad motivation, then weaken, transform or even wipe out the danger at the beginning through massive ideological and political education.

\section{TAKING APPROPRIATE MOTIVATING MEANS IN IDEOLOGICAL AND POLITICAL EDUCATION}

Motivation is the internal psychological process and the main means to generate human enthusiasm; it can stimulate people's motivation, dig people's potential and improve behavior efficiency so as to promote people's power to achieve the target objectives. Behavioral science holds that motivation is a key issue in management. The consistency of educational object and work task in ideological and political education and behavioral science determines that the ideological and political education can absorb and introduce the motivation theory of behavioral science. Both have to work in people and mobilize people's enthusiasm according to people's psychological development discipline. Therefore, it is able to use the valuable results of the behavioral science motivation theory to do the ideological and political education under the new situation, and appropriate motivation can change external stimulation into internal selfconscious behavior and mobilize people's enthusiasm.

So, how to introduce the motivation theory of behavioral science into the ideological and political education to mobilize the enthusiasm of the education object? According to the three main types of motivation theory, I think we can learn from the following three aspects.

\section{A. Employ Need-based Motivation Theory to Mobilize People's Enthusiasm According to the Various Needs of the Objects}

The need-motivation theory holds that the need is the driving force of people's behavior, and it is necessary to start from the need to stimulate people's behavior motivation. According to Maslow's hierarchy of needs theory, our ideological and political education should mobilize the enthusiasm of the educational object. First of all, the education has to meet people's physiological needs and safety needs so that their basic life can be guaranteed without worries. Secondly, the ideological and political education can create a pleasant interpersonal atmosphere, enhance education objects' sense of identity and belonging to collectivity and meet their social needs and love needs by coordinating interpersonal relationships and resolving interpersonal conflicts. Thirdly, ideological and political education should meet people's needs for self-esteem and others' respect so as to make people feel being cared and recognized by others, so people can realize their own values and devote themselves to the study and work with sufficient confidence and enthusiasm. Finally, ideological and political education needs to mobilize the enthusiasm of the education objects and special attention should be paid to stimulate the self-realization needs of education objects so that they can see their own achievements and have the sense of pride that they can shoulder the responsibility for others and society and make their own contributions. Thus people will fully show their own intelligence and enthusiasm to make their own values being perfectly realized.

\section{B. Employ Process-based Motivation Theory to Set Appropriate Motivation Goals, thus Mobilizing the Enthusiasm of Educational Objects}

Process-based incentive theory holds that human behavior is oriented to a certain goal; the goal set plays an important role in guiding the people's behaviors. The goal can also be used as a motivating factor to mobilize the enthusiasm of people. Reflected in the ideological and political education, such a process should be reflected: First of all, according to the overall goal of ideological and political education and the objects' thought and ability, we can set the specific goal through the motivation of maximally meeting the current needs of the object of education and what is most likely to be achieved through the efforts. Second, the specific objectives that have been identified are clarified. This will not only meet the needs of the objects, but also improve the acceptability of the target, is conducive to the educational object to play their own initiative. Finally, the results of the target were evaluated. To affirm and praise what the objects are supposed to continue through the positive reinforcement. To deny and punish what the objects are supposed to avoid through negative reinforcement.

\section{Employ State-based Motivation Theory to Create a Good External Environment, thus Mobilizing the Enthusiasm of Educational Objects}

State-based incentive theory holds that the need to meet the unfairness of the way and the need to meet the setbacks, will affect the enthusiasm of people. If ideological and political education is to mobilize the enthusiasm of educational objects, we must first eliminate these unfair. For the existence of injustice, we need to correct; for personal awareness on the subjective one-sidedness caused by the sense of injustice, we need to give the right to guide, to correct their psychological bias. Second, ideological and political educators should also use the theory of scientific frustration to help the frustrated people to calmly analysis, establish a correct setbacks outlook, change the environment, and ultimately overcome the negative sentiment by the setbacks, turn the failure Lessons to the driving force for success, to maintain the enthusiasm of learning work.

\section{CONCLUSION}

As a consequence, it should be pointed out that ideological and political education can learn from the behavioral science, but cannot be equated with behavioral science. Behavioral science is a research method that studies the objective world from the perspective of the interaction between the individual and the society. It is of great significance for us to explore the human potential and fully mobilize the enthusiasm and creativity of the people. On the 
other hand, the behavioral science overly emphasizes the role of individualism and utilitarianism, ignoring human sociality and dedication. We should have a scientific attitude towards the theory of behavioral science; this method is not desirable to completely separate the ideological and political education from behavioral science or to replace the ideological and political education with behavior science.

\section{REFERENCES}

[1] Marx, K. H., Engels, F. Marx and Engels Complete Works Volume 1[M]. Beijing: People's Publishing House, 1956: 82 (in Chinese)

[2] Maslow, A. Humanistic Philosophy[M]. Beijing: Beijing Jiuzhou Publishing House, 2003 (in Chinese)

[3] Qiu Weiguang. Principles of Ideological and Political Education[M]. Beijing: Higher Education Press, 2002 (in Chinese)

[4] Sun Tong. Organizational Behavior[M]. Beijing: China Materials Publishing House, 1986 (in Chinese)

[5] Liu Fengrui. Behavioral Science Foundation[M]. Shanghai: Fudan University Press, 1991 (in Chinese) 